\title{
The relationship between environment operational performance and environmental disclosure of Nigerian listed companies
}

\begin{abstract}
The increase in natural resources consumption by Nigerian companies has raised concern about environmental impact of such activities. Nigerian government and other stakeholders pressured these companies to be environmentally friendly or risk their legitimacy. This obliges the companies resort to environmental disclosure to counter the theat. However, the disclosure is doubted whether it is a true reflection of the performance. This is due to a green-wash problem, where those companies whose legitimacy is threatened present high-level of disclosure to avoid sanctions. Though, voluntary disclosure theory asserts that high-performing companies disclose quality environmental items to achieve favourable selection from the stakeholders. This study examined the relationship between the environment operational performance and environmental disclosure of the companies listed in the Nigerian Stock Exchange. A survey method and content analysis of the companies' annual reports was used to obtain data on the performance and the disclosure. Where OLS, 2SLS and 3SLS regression analysis showed a significant negative relationship between the environment operational performance and overall environmental disclosure and disclosure level. However, there is no statistical evidence to support the relationship between the performance and disclosure quality. This study contributes to the understanding of the green-wash issue about environmental disclosure by the Nigerian companies. It unveils non-appreciation of quality disclosure by the companies to achieve selection preference. Also, the use of environment operational performance measure provides an alternative approach to the test of the relationships. The limitation of the study is hinged in using cross-sectional data and its small sample size.
\end{abstract}

Keyword: Environment operational performance; Environmental disclosure; Green wash problem; Nigerian companies 